\title{
Implementation of Digital Marketing Strategy for Improving UMKM Website Promotion (Case Study: Rumah Mesin)
}

\section{Penerapan Strategi Digital Marketing Untuk Peningkatan Promosi Website UMKM (Studi Kasus: Rumah Mesin)}

\author{
Choiruddin, Tikaridha Hardiani \\ \{udinchoir11@gmail.com, tikaridha@unisayogya.ac.id\}
}

Program Studi Teknologi Informasi, Fakultas Sains dan Teknologi, UNISA Yogyakarta

\begin{abstract}
The advancement of information technology is increasingly rapid, so search engines are the main choice as a medium for marketing products and services, and also for increasing the popularity of a website's existence. The main problem faced by the company CV. The machine house is competition in the world of machinery that is so fierce that the internet is needed to help it compete with the company's competitors. The way this is done is by promoting using SEO (Search Engine Optimization) Digital Marketing techniques. This research was carried out on a website where initially the techniques of SEO were just not optimal, then by applying the SEO on Page method such as keyword optimization in the title tag, content, meta keywords, meta description, at this stage several tests were also carried out as benchmarks for the success of implementing SEO techniques. The results of the application of SEO techniques are able to increase the SERP (Search Engine Results Page) of the website in search engines and successfully indexed by Google to be on the first page of page 9 in the second month.
\end{abstract}

Keywords - CV. Rumah Mesin; Digital Marketing; Search Engine; SEO

\begin{abstract}
Abstrak. Kemajuan teknologi informasi yang semakin pesat, maka mesin pencari merupakan pilihan utama sebagai media untuk memasarkan produk dan layanan jasa yang dimiliki, dan juga untuk meningkatkan popularitas dari keberadaan sebuah website. Masalah yang sekarang dihadapi perusahaan CV. Rumah Mesin adalah persaingan dalam dunia permesinan yang begitu ketat, sehingga dibutuhkannya media internet dalam membantu untuk bersaing dengan kompetitor perusahaan. Cara yang dilakukan yaitu dengan mempromosikan menggunakan teknik SEO (Search Engine Optimization) Digital Marketing. Peneltian ini dilakukan pada sebuah website yang awalnya sudah dilakukan teknik-teknik dari SEO hanya saja kurang maksimal, kemudian untuk penerapan metode SEO onPage yaitu optimasi keyword pada title tag, content, meta description, meta keyword dan pada tahap ini dilakukan juga beberapa pengujian sebagai tolak ukur keberhasilan penerapan teknik-teknik SEO. Hasil dari penerapan teknik-teknik SEO itu dapat meningkatkan SERP (Search Engine Results Page) website di mesin pencari dan berhasil terindeks oleh google berada di page pertama halaman 9 pada bulan kedua.
\end{abstract}

Kata Kunci - CV. Rumah Mesin; Digital Marketing; Mesin Pencari; SEO

\section{Pendahuluan}

Teknologi yang semakin canggih mempermudah manusia untuk berbisnis, salah satunya yaitu lebih mudah mengenalkan perusahaan serta membantu dalam memasarkan produk. Salah satu perusahaan yang memakai internet sebagai media untuk mengenalkan perusahaannya yaitu perusahaan CV. Rumah Mesin yang. bergerak dibidang permesinan. Perusahaan CV. Rumah Mesin ini memiliki beberapa cara untuk mampu mengenalkan perusahaan dan produknya, namun ada beberapa masalah juga yang lambat laun harus mendapatkan solusi agar tidak dapat menjadi masalah serius apabila diabaikan.

Masalah utama yang sekarang dihadapi perusahaan CV. Rumah Mesin adalah persaingan yang begitu ketat di bidang penjualan permesinan, sehingga diperlukannya media internet dalam membantu CV. Rumah Mesin bersaing dengan kompetitor perusahaan. Dengan begitu CV. Rumah Mesin menggunakan Search Engine Optimization agar dapat bersaing menampilkan website CV. Rumah Mesin pada halaman pertama pada indeks mesin pencarian Google. Search engine atau mesin pencari merupakan perangkat lunak atau bisa juga di sebut dengan robot atau jaring laba laba yang diprogram untuk mencari situs-situs baru[8]. SEO (Search Engine Optimization) merupakan sebuah teknik yang sering digunakan untuk memaksimalkan suatu website agar lebih dikenal atau lebih mudah dibaca oleh mesin pencari sehingga dapat muncul pada halaman awal mesin pencari sehingga menyebabkan akan memiliki pengunjung yang banyak [4]. Namun pengoptimalan untuk website dengan Search Engine Optimization (SEO) hanya terfokus pada website utama saja sehingga hasil yang didapat tidak optimal, sebab website di dalam perusahaan diibaratkan berbentuk seperti piramida, jadi di puncaknya itu terdapat website utama dan di bawahnya ada beberapa website 
pembantu, sehingga setiap website pembantu juga memiliki beberapa sub website di bawahnya, sehingga bila semua komponen website ini disatukan akan terlihat seperti piramida.

CV. Rumah Mesin juga memanfaatkan skema website piramida tersebut yaitu yang di puncaknya terdapat website utama dan di bawahnya ada beberapa website pembantu. Perusahann CV. Rumah Mesin juga mengunakan website pembantu untuk mendongkrak website utama dapat tampil di halaman pertama Google. Tentunya pengelolaan pada website pembantu dan sub websitenya haruslah tepat, sebab kualitasnya sangat mempengaruhi peringkat website utama untuk tampil di halaman pertama Google. Maka dari itu diterapkan juga metode Search Engine Optimization (SEO) pada website pembantu dan sub websitenya agar kualitasnya sesuai standar Google sehingga membantu website utama tampil di halaman pertama Google. Penggunaan website pembantu itu juga dapat menunjang dalam pemasaran produk yang sesuai dengan kategori produknya, karena dibeberapa bagian website yang berkaitan dengan produk pada website utama akan diberikan backlink atau tautan menuju website utama. Semakin banyak link yang dimiliki maka akan mendapatkan peringkat yang lebih baik dari mesin pencari[10].

Mesin pencari mempunyai kemampuan dalam menelusuri informasi-informasi baik dalam bentuk file, gambar, video, atau jenis-jenis berkas lainya yang sudah dipublikasikan dan yang dibutuhkan dengan memasukan kata kunci kemudian mesin pencari akan menelusuri secara otomatis terkait informasi yang berhubungan dengan kata kunci tersebut sehingga pengguna dapat menemukan informasi dengan mudah dan lebih cepat[9]

Metode Search Engine Optimization (SEO) yang digunakan oleh perusahaan CV. Rumah Mesin ada dua yaitu metode SEO Onpage dan SEO Offpage. SEO Onpage merupakan teknik SEO yang dilakukan langsung pada halaman websitenya. Penggunaan teknik SEO Onpage ini menggunakan plugin untuk melakukan pengecekan apakah artikel yang dibuat di website tersebut sudah memenuhi standar Google atau belum. Plugin yang digunakan oleh CV. Rumah Mesin untuk SEO Onpage-nya ini yaitu Yoast SEO karena indikatornya yang sudah cukup lengkap. SEO Offpage merupakan teknik SEO yang dilakukan diluar website tersebut dan teknik SEO ini dilakukan secara manual antar sesama website atau dapat juga bisa menggunakan jasa iklan. Karena perusahaan CV. Rumah Mesin memiliki sejumlah website pembantu dan sub website, maka teknik SEO Offpage yang digunakan yaitu antar sesama website. Namun sekarang ini teknik SEO offpage banyak dilakukan antar sesama artikel pada website yang sama, maka dari itu ada istilah inbound link dan outbound link. Inbound link merupakan tautan yang mengarah ke sebuah artikel didalam website yang sama, sedangkan outbound link merupakan tautan yang mengarah ke sebuah artikel atau website yang berbeda. Teknik-teknik yang dilakukan meliputi optimasi dari penggunaan teks, gambar, tag-tag, struktur URL (Uniform Resource Locator), link internal, penggunaan header dan isi konten dari sebuah halaman web[2].

Penggunaan SEO untuk website pembantu dan sub website-nya dapat bermanfaat bagi CV. Rumah Mesin agar mempermudah dalam pengelolaan konten media pada website, dan juga menjadi solusi alternatif untuk pemasaran produk dengan banyaknya website pembantu dan sub website-nya dalam satu perusahaan dengan berbagai produk yang akan ditawarkan, tentunya akan saling meningkatkan promosi dan pemasaran produk, juga akan meningkatkan hasil pencarian dan peningkatan income bagi perusahaan tersebut. Manfaat dari penggunaan website pembantu dan sub domain sendiri yaitu dapat menghasilkan informasi serta penyusunan artikel dan postingan produk yang lebih detail, cepat, tepat, akurat dan dapat diakses dimana saja, sesuai dengan yang dibutuhkan dan akan mempermudah dalam meningkatkan peringkat SEO agar lebih optimal.

\section{METODE}

Jenis penelitian ini adalah studi kasus, karena penelitian ini menggunakan pendekatan kualitatif yaitu suatu proses penelitian dan pemahaman yang berdasarkan pada metode yang menyelidiki suatu fenomena sosial dan masalah manusia, landasan teori dipergunakan sebagai pemandu agar fokus penelitian sesuai dengan fakta di lapangan.

\section{A. Alat dan bahan}

Alat dan bahan yang digunakan berupa perangkat keras (hardware) dan perangkat lunak (software) sebagai berikut:

- Perangkat keras (hardware) dengan spesifikasi sebagai berikut: Laptop

1) Processor : Intel(R) Core(TM) i7 CPU M620@2.67GHz

2) Memory : 4 GB DDR3

3) Monitor : 14" HD LED

4) Hard Disk : 320 GB ATA

5) VGA : Intel(R) Centrino(R) Advance-N 6200 AGN

- Perangkat lunak (software) dengan spesifikasi sebagai berikut:

1) Sistem Operasi : Microsoft Windows 7 Ultimate

2) SEO Tools : Yoast SEO

3) Web Utama : rumahmesin.com

4) Web Pembantu : brangkas.id

\section{B. Alur penelitian}

Berikut alur penelitiannya: 


\section{Survei pustaka}

Survey pustaka digunakan untuk memperoleh data yang ada hubungannya dengan permasalahan baik yang didapat dari buku-buku teori yang membahas mengenai penerapan SEO, hasil-hasil seminar, ataupun jurnal-jurnal yang mempunyai korelasi terhadap kegiatan penelitian ini

\section{Wawancara}

Wawancara digunakan untuk mendapatkan informasi sedetail dan selengkap mungkin yang berkaitan dengan pelaksanaan penelitian dan penerapan SEO di perusahaan CV. Rumah Mesin. Wawancara ini menghasilkan beberapa teknik SEO yang diterapkan di website Rumah Mesin dan website pendukungnya.

\section{Penerapan seo}

Alur penelitian ini merupakan pengimplementasian dari hasil analisis dan pengumpulan data yang sesuai dengan kebutuhan produk dan artikel yang akan di posting di website dengan metode On Page dan Off Page..

\section{Hasil dan Pembahasan}

\section{A. Jenis teknik seo}

Seo on page

Di bawah ini tahapan- tahapan dari SEO Onpage antara lain [1]):

a) Title

Yaitu pengoptimalisasikan penetapan title pada artikel.

b) Meta Description

Yaitu pemberian keyword pada artikel agar website mudah dideteksi oleh search engine meliputi tiga kategori yaitu meta title, meta description dan meta keyword. Penggunaan meta title dan meta description yang sesuai dan tepat.

c) Heading Tags

Yaitu pengoptimalisasian pada heading pada artikel. Karena optimasi SEO terfokuskan pada heading tag H1, lalu pada tag $\mathrm{H} 2$ dan seterusnya. Tetapi penggunaan heading tag ini tidak perlu semua 6 elemen HTML untuk membentuk halaman.

d) URL Structure

Optimalisasi struktur url di setiap halaman website.

e) Image Optimization

Yaitu optimalisasian pada gambar dengan cara memberikan tag ALT dan tag TITLE pada setiap gambar yang di posting untuk mendefinisikan gambar tersebut.

f) Konten

Optimalisasi konten pada halaman website yang membantu website untuk muncul di search engine.

Seo off page

SEO Off Page merupakan sebuah proses dalam optimalisasi halaman di luar faktor website [7]. Di bawah ini tahapan- tahapan dari SEO Offpage antara lain [1] :

a) Internal Link

Optimalisasi link artikel lain yang masih dalam website yang sama.

b) Backlink

Backlink yaitu link dalam sebuah website yang mengarah ke alamat website. Bisa mengarah ke alamat website itu sendiri ataupun ke website lain [6].

\section{B. Penerapan seo}

\section{Riset kata kunci}

Melakukan riset kata kunci merupakan teknik SEO yang dipergunakan untuk menentukan kata kunci (keywords) yang akan digunakan pada sebuah postingan atau artikel, dengan melakukan riset keyword tersebut maka secara otomatis akan mudah untuk mengetahui apa saja yang sedang trend di google. Karena penggunaan kata kunci merupakan bagian inti atau utama dalam teknik SEO, pemilihan kata kunci memiliki peranan yang sangat penting dalam menentukan inti dari halaman website dan kemudian gabungan dari kata-kata kunci yang membentuk sebuah frasa sehingga akan menghasilkan pola pencarian yang akan menampilkan hasil yang lebih akurat[3]. 
Pembuatan artikel sesuai keyword akan membantu dalam memecahkan frasa menjadi bagian- bagian komponennya, karena teknik SEO mengacu pada optimasi search engine, atau proses pengoptimalan sebuah website sehingga orang dapat lebih mudah menemukannya melalui mesin pencari seperti Google. Dengan kata kunci atau "keyword", bisa diartikan bahwa informasi apa pun yang dicari ada di konten web, sehingga informasi dapat dikonsumsi dengan baik.

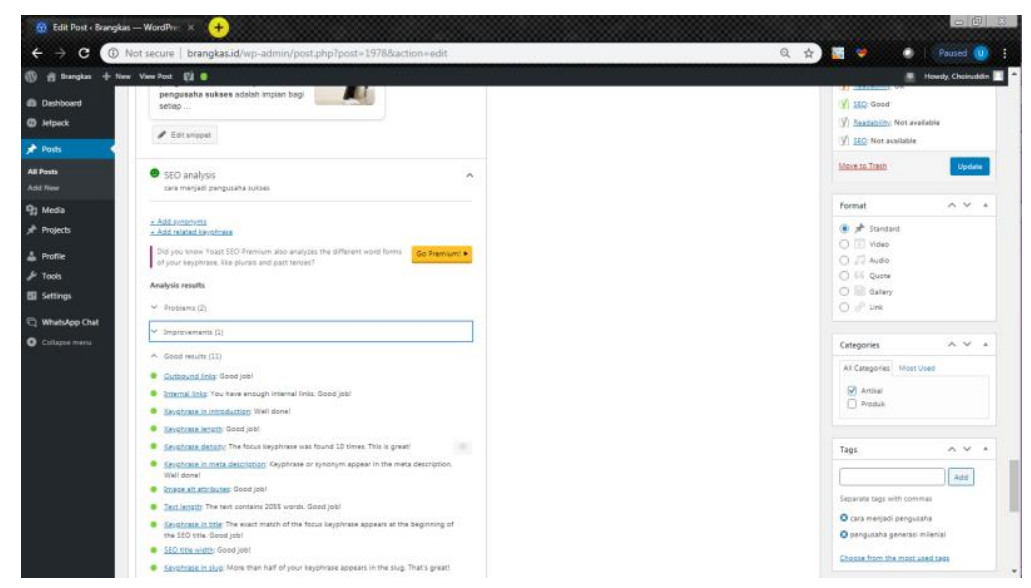

Gambar 1. Proses pembuatan artikel

Dalam proses pembuatan artikel harus sesuai dengan keyword yang sudah kita riset terdapat pada Gambar 1, maka dengan begitu artikel kita dapat muncul dihalaman pertama mesin pencarian.

\section{Pengecekan plagiarism}

Pengecekan plagiarism dilakukan dari artikel yang sudah ditulis. Caranya yaitu teks artikel disalin terlebih dahulu di mesin pengecekan plagiat, mesin pengecekan plagiat yang saya gunakan yaitu menggunakan website smallseotools. Website pengecekan plagiat ini untuk melihat seberapa presentase artikel tersebut plagiat atau tidak dan pada website tersebut juga dapat mengetahui teks atau bagian mana yang merupakan plagiat, dapat dilihat pada Gambar 2.

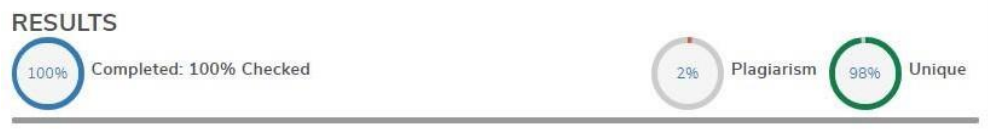

Gambar 2. Cek plagiarism

Untuk pengecekan plagiarism ini setidaknya minimal $30 \%$ untuk plagiarism dan minimal $70 \%$ tidak plagiarism.

Pengecekan seo (title tag, content, meta keyword, meta description)

Pengecekan SEO (title tag, content, meta keyword, meta description) yaitu pengecekan SEO agar mengetahui apakah sudah sesuai pada sebuah website untuk mendukung keyword ataupun judul dari sebuah blog itu sendiri. Penggunaan keyword yang menarik dan memaksimalkan keyword pada artikel yang dibuat dengan jumlah kata yang sudah di tentukan dan tidak boleh berlebihan juga.

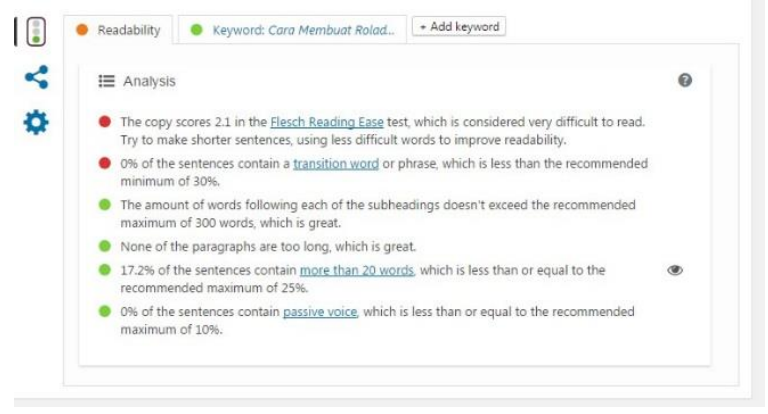

Gambar 3. Pengecekan SEO

Untuk keterangan bagus tidaknya artiker sesuai SEO yaitu nilai hijau $=$ good, orange $=$ oke dan merah $=$ perlu diperbaiki lagi dapat dilihat pada Gambar 3. Kata kunci atau keyword yang baik menjadi sangat penting untuk menjamin bahwa ketersediaan informasi mengenai website / blog di internet. Hal ini yang manjadi pengaruh pada seberapa banyaknya pengunjung yang bakal berkunjung ke suatu website/blog. Semakin banyak informasi tentang suatu hal tersebar di internet, maka semakin besar pula kesempatan pengembangan pemasaran pada website / blog tersebut. 
Upload artikel

Jika artikel sudah selesai dan sesuai dengan SEO maka langkah terakhir yaitu posting artikel di website brangkas.id.

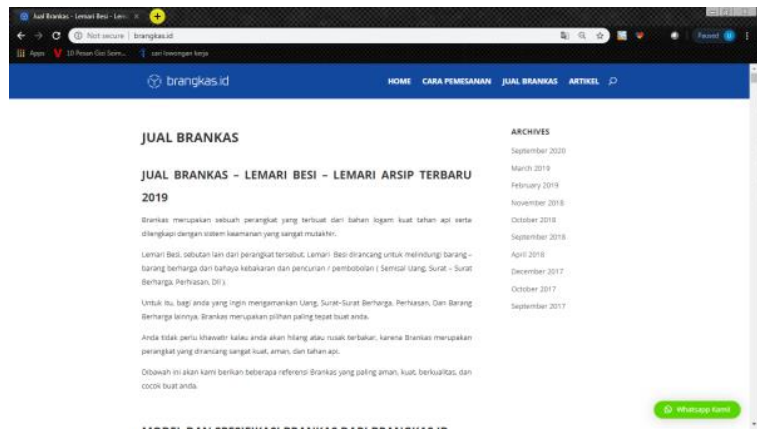

Gambar 4. Upload artikel

Dalam proses upload pada Gambar 4 ini usahakan diperhatikan kerapian mulai dari penulisan ataupun peletakan gambar, karena dengan artikel yang rapi dan baik akan menarik pengunjung untuk membaca dan tidak membosankan.

\section{Pengujian}

Jika semua tugas pembuatan artikel sesuai dengan standar SEO yang dilakukan maka diperoleh hasil peringkat dari artikel tersebut. Berikut adalah implementasi pengujian dengan SERPmojo dari kata kunci (keyword) yang terdapat pada artikel di website brangkas.id dan hasil ranking pada pencarian google, mendapatkan peringkat 9 dengan kata kunci tempat menyimpan dokumen penting yang terdapat pada Gambar 5 di bawah ini.

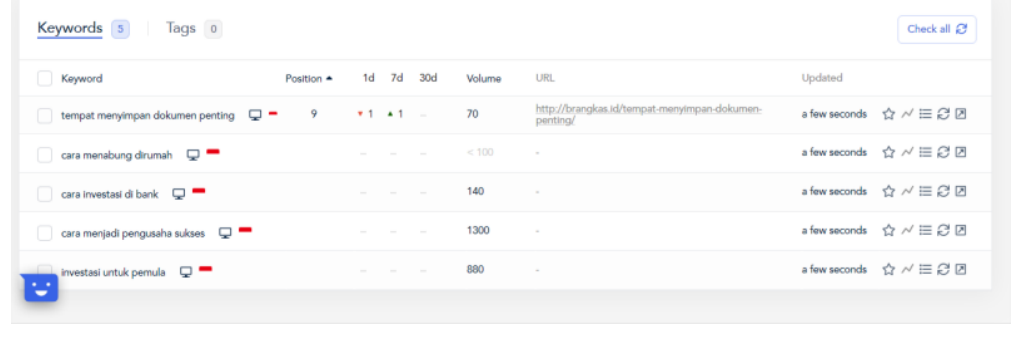

Gambar 5. Pengecekan dengan SERPmojo

Untuk memastikan akurasi dari peringkat artikel maka kami melakukan pengecekan manual dari peringkat artikel yang dibuat dengan cara memasukan kata kunci (keyword) artikel tersebut dipencarian Google, contoh untuk pengecekan manual hanya dilakukan pada artikel yang memiliki peringkat paling tinggi saja agar lebih mudah. Berikut hasil pengecekan artikel dengan kata kunci tempat menyimpan dokumen penting secara manual di mesin pencarian google berada pada posisi 9 di halaman pertama.

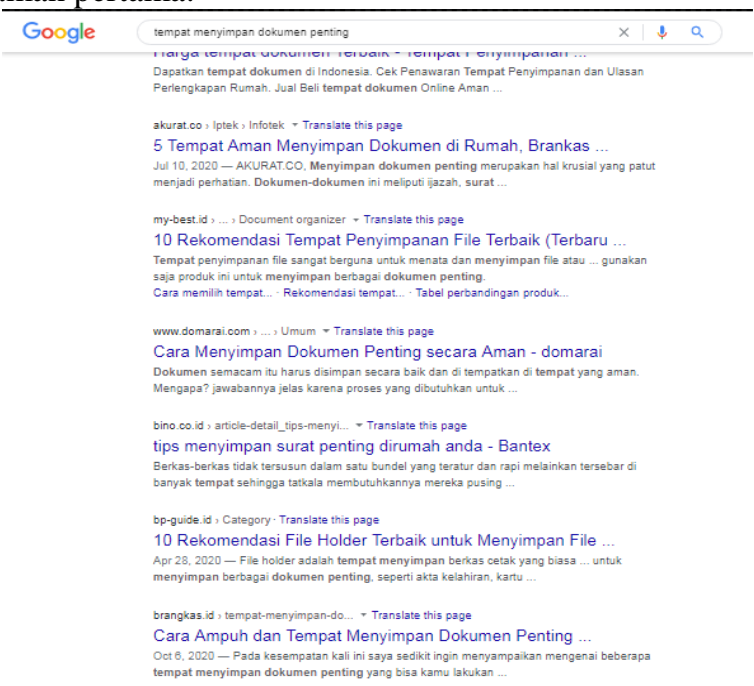

Gambar 6. Pengecekan SEO secara manual 
Pengecekan manual ini dilakukan dengan menuliskan kata kunci (keyword) di mesin pencarian dan mencari artikel yang kita tulis secara manual. Dan dari pengecekan manual ini, artikel yang kami tulis berada di posisi 9 di halaman pertama, dapat dilihat pada Gambar .6.

\section{KESIMPULAN}

Kesimpulan yang dapat penulis ambil dari penelitian ini yaitu dalam penerapan teknik SEO untuk mencapai halaman pertama di mesin pencari google yang diselenggarakan di CV. Rumah Mesin : perlunya dilakukan penerapan SEO pada website pendukung dan sub wesite CV. Rumah Mesin agar mencapai halaman pertama mesin pencari Google, metode SEO yang digunakan untuk mengoptimalkan website pendukung dan sub website-nya yaitu SEO Onpage dan Offpage. Pengecekan peringkat website dengan tools yang digunakan memiliki akurasi tepat setelah dibandingkan dengan pengecekan secara manual. Beberapa dari artikel pada setiap website brangkas.id mampu tampil dihalaman pertama mesin pencarian Google. Artikel yang memiliki peringkat kecil dan bahkan tidak memiliki peringkat dikarenakan penulisan yang kurang tepat dan ketidaksesuaian dengan kata kunci. Hasil dari penerapan teknik-teknik SEO yang kami lakukan mampu meningkatkan SERP (Search Engine Results Page) website di mesin pencari dan berhasil terindeks di google berada pada page pertama halaman 9 pada bulan kedua dengan kata kunci tempat menyimpan dokumen penting.

\section{UCAPAN TERIMA KASIH}

Terima kasih kepada Ibu Tikaridha Hardiani, S.Kom., M.Eng sebagai dosen pembimbing yang telah membimbing dan memberikan pengarahan selama penelitian. Terima kasih kepada seluruh pihak dari CV. Rumah yang telah membantu dan memberi semangat dalam pengerjaan penelitian ini.

\section{REFERENSI}

[1] Riyanto, A. (2018). Analisis dan Penerapan Search Engine Optimization Pada Website Menggunakan Metode White Hat SEO (Studi Kasus di PT. Suryaputra Adipradana). Jurnal Teknologi Informasi.

[2] Halilintar, R. B., \& Ariyus, D. (2018). Implementasi Seo ( Search Engine Optimization ) Pada Website Agc ( Auto Generated Content) Untuk Meningkatkan Serp ( Search Engine Result Page ) Studi Kasus : Website Gallery (pp. 13-18).

[3] Himawan, Arisantoso, \& Saefullah, A. (2017). Search Engine Optimization (SEO) Menggunakan Metode White Hat SEO Untuk Meningkatkan Peringkat dan Trafik Kunjungan Website. In Seminar Nasional Teknologi dan Informatika 2017 (pp. 783-790).

[4] ID hadiana, A. (2018). Model Search Engine Optimization bagi Usaha Mikro Kecil dan Menengah ( UMKM ) di Bandung Barat. JUMANJI (pp. 31-38).

[5] Riyanto, A. (2018). Analisis Dan Penerapan Search Engine Optimization Pada Website Menggunakan Metode White Hat Seo. JURNAL TEKNOLOGI INFORMASI.

[6] Riyanto, A. D., \& Purwadi. (2016). Penerapan Teknik Search Engine Optimization ( SEO ) untuk Memenangkan Persaingan Kata Kunci pada Mesin Pencari Google ( Implementation Techniques Search Engine Optimization ( SEO ) for Winning Competition Keywords on Google Search Engines ( Case Study : C. JUITA Jurnal Informatika.

[7] Nurjaya, W., \& Riyanto, N. (2017). ANALISIS DAN PENERAPAN SEARCH ENGINE OPTIMIZATION PADA WEBSITE MENGGUNAKAN METODE WHITE HAT SEO (STUDI KASUS DI PT.SURYAPUTRA ADIPRADANA).

[8] Sujatmiko, S., \& Ariyus, D. (2018). Analisis Google Image Index Perbandingan SEO Expired Domain dan Fresh Domain Studi Kasus Toko Online (pp. 25-30).

[9] Handayani, I., Febriyanto, E., \& Shofwatullah, M. (2019). Optimalisasi Visibilitas Situs iLearning Journal Center (iJC) pada Mesin Pencari Berbasis Search Engine Optimization (SEO) On Page. Sains dan Teknologi Informasi.

[10] Hayaty, M., \& Meylasari, D. (September 2018). Implementasi Website Berbasis Search Engine Optimization (SEO) Sebagai Media Promosi. JURNAL INFORMATIKA, (pp. 295-300). 